\title{
CONTROL OF CONTINUOUS RHEOCASTING PROCESS USING HEAT FLOW MODEL
}

Abdel-Wahed M. Assar, Nahed A. El-Mahallawy, Mohamed A. Taha and Ahmed S. El-Sabbagh

Dept. of Mechanical Design and Production Engineering, Faculty of Engineering, Ain- Shams Uinversity Abaseia, Cairo, Egypt

\section{ABSTRACT :}

In the continuous rheocasting process, a semi-solid alloy is obtained from the exit port of the apparatus at a given rate and with a yiven fraction solid. This fraction solid is dependent on the corresponding temperature within the solid-liquid range. which should be controlled accurately by the process parameters for a given rheocaster stirring chamber.

For this purpose a heat flow model has been established for the continuous rheocasting of Bi-17wtrsn alloy. The heat transfer calculations are based on the solution of the two-dimensional partial differential equations using a finite difference method. An excellent agreement between calculations and experimental results is found. Computations are carried out in order to find the influence of stirring chamber dimensions on the alloy exit temperature and therefore, the volume fraction solid. The influence of input metal temperature and metal flow rate on the exit temperature and volume fraction solid are also found. 


\section{INTRODUCTION:}

During the last decade, considerable research work has been directed towards the improvement of alloy properties in the as cast condition by applying some innovative casting processes [1]. One of the processes which shows remarkable improvement -in soundness, homogeneity and structure is the rheocasting (or stirr-casting) process. This process consists of vigorously agitating the alloy in the solid-liquid temperature range, to temperature between $t$ he liquidus and solidus. There are two techniques either batch type of continuous type rheocasting. The continuous type is more suitable for practice [3].

Many publications have appeared on the process studying slurry rheological behaviour and as-cast properties such as soundness, structure, homogeneity, mechanical properties and deformability [4-12]. These publications indicate many promising aspects of the process and as-cast properties produced. However, the application of the process on industrial scale is still very limited due to the difficulty in controlling the process parameters.

This paper is a part of a research program which tries to contribute in solving this problem. A heat transfer model, which gives the temperature gradient produced in Bi17 wrsn alloy contained inside a continuous rheocaster, is presented. The influence of rheocaster dimensions and other process variables on the temperature of the produced slurry is obtained.

\section{Experimental set up and procedure:-}

Rheocasting:

The continuous rheocasting consists mainly of an upper cylindrical crucible made of austenitic cast-iron and a lower smaller cylindrical stirring chamber located on the same axis. The upper chamber (crucible) has $175 \mathrm{~mm}$. internal diameter and $240 \mathrm{~mm}$. height while the lower chamber (stirring chamber) has $39.6 \mathrm{~mm}$. internal diameter and $200 \mathrm{~mm}$. height. Four electrical resistance coils of 4 $\mathrm{KW}$ are used to heat the upper chamber. These coils are connected to a transformer with a built in temperature controller to regulate the temperature inside the chamber with $\pm 2 k$. Additional resistance coils, used to heat the etirring chamber, are also connected to another transformer with a temperature controller. The temperature of the air gap existing between the coils and the stirring chamber was controlled between these coils and the stirring chamber was also controlled within $\pm 2 \mathrm{~K}$. At the same time a cooling coil (copper tube) is installed around the stirring chamber and connected to a water bath with a 
were used to produce an appropriate temperature gradient in the alloy along the axis of the stirring chamber. The value of the temperature gradient will determine the temperature and consequently the volume fraction solid at the exit port. Metal flow through this port was controlled by the vertical position of the stirrer, which is a stainlese steel bar $(35.6 \mathrm{~mm}$. in diameter and $510 \mathrm{~mm}$. long) with a hemispherical lower end. The lower part of the stirrer which is inserted in the stirring chamber has a special shape in order to get an efficient agitation action. The stirrer was powered by $1.8 \mathrm{KW}, 3000 \mathrm{rpm}$ D.C. motor connected to a speed control unit to achieve a constant speed with the variation of the torque. The alloy was solidified gradually during its downward flow in the stirring chamber while it is subjected to vigorous agitation provided by the stirrer. To prevent the freezing of the alloy below the exit port in the case of noncontinuous flow, an additional resistance heater was placed at the exit port of the rheocaster to heat its vicinity to a temperature equals to the exit temperature of the slurry $\pm 5 \mathrm{~K}$. Five Chromel-Alumel thermocouples were set in the wall of the stirring chamber along its height and were connected to five channel chart recorder.

Rheocasting experiments:-

Before starting the process, the charge in the upper and middle chamber was heated to a temperature about $40 \mathrm{~K}$ above the liquidus. After complete melting, the stirrer was set in motion at the desired speed. The power in the bottom coil was set on to keep the exit nozzle temperature at the appropriate level while that in the middle coil was set to keep the atmospheric temperature around the cooling coil at the appropriate level. Once the slurry temperature has reached the required level and consequently the desired volume of the solid fraction, the stainless steel stirrer was raised from the exit port and the slurry started flowing out. The flow rate was controllod by adjusting the position of the stirrer inside the stirring chamber. The amount of heat extracted from the stirring chamber was controlled by the input temperature of the cooling water and the temperature of the controlled furnace (consequently the atmospheric temerapture around the cooling coill. Since the amount of heat was kept constant, therefore the volume fractionn solid at the exit port of the stirring chamber will be inversely proportional to the flow rate and input temperature. During the flow of metal slurry in the etirring chamber, the input temperature is kept above the liquidus. Once the thermocouples readingsindicate that steady state has been reached, the metal slurry was quenched in a cooled copper mould ( $4 \mathrm{gm}$.$) with a cylindrical cavity ( 8 \mathrm{~mm}$. diameter, 8
$\mathrm{~mm}$. height). 


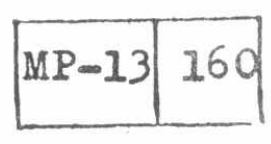

\section{Heat Elow Mode1:}

In the continuous rheocasting process, the molten metal flows from the large chamber which consists of a reservoir, and enters the stirring chamber at a temperature $20 \mathrm{~K}$ above the liquidus temperature figure 1 . The stirring chamber is subjected to a radiative heat from the furnace, natural convection from the air present in the furnace - chamber gap, and to conductive cooling of the cooling coils, as shown in Fig. 1. At the bottom of the stirring chamber, a resistance furnace is present to keep the temperature of the atmosphere equal to the exit temperature of the slurry. As the melt flows downwards in the stirring chamber with a consistant speed, steady state condition is reached and the process can be considered similar to the steady state continuous casting.

The heat tranefer calculatins are based on the golution of the two dimensional steady state partial differential equations given by:

$K\left(d^{2} T / d z^{2}+d^{2} T / d r^{2}+(1 / r) d T / d r\right)+q-c_{p} v(d T / d z)=0$

It is to be noted that:

- The term $K\left(d^{2} T / d z^{2}\right)$ corresponds to the variation of temperature parallel, to the axis of the stirring chamber. - The term $K\left(d^{2} T / d r^{2}+(1 / r) d T / d r\right)$ corresponds to the radial temperature variation.

- The term C V (dT/dz) corresponds to the thermal capacity due pto the longitudinal displacement of the slurry. Q corresponds to the evaluation of latent heat due to change in phase.

\section{As sumptions:-}

The assumptions used in the calculation are:

1. No heat flow between slurry and surrounding atmosphere at the exit port of the stirring chamber.

2. The temperature of the cooling water is taken as the average of the input and output temperature.

3. As the melt cools in the stirring chamber, heat flow will be only by conduction in both liquid and semi-solid state.

4. There is a heat flow resistance at metal/stirrer, metal/stirring chamber interfaces and between cooling coll and external wall of the stirring chamber. Values of the heat flow resistance are first assumed then adjusted according to experimental results. 


\section{\begin{tabular}{|l|l|}
\hline$M P-13$ & 161 \\
\hline
\end{tabular}}

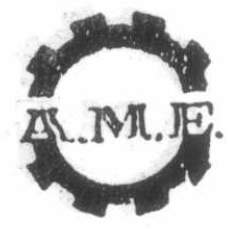

SECOND A.M.E. CONFERENCE

$r$
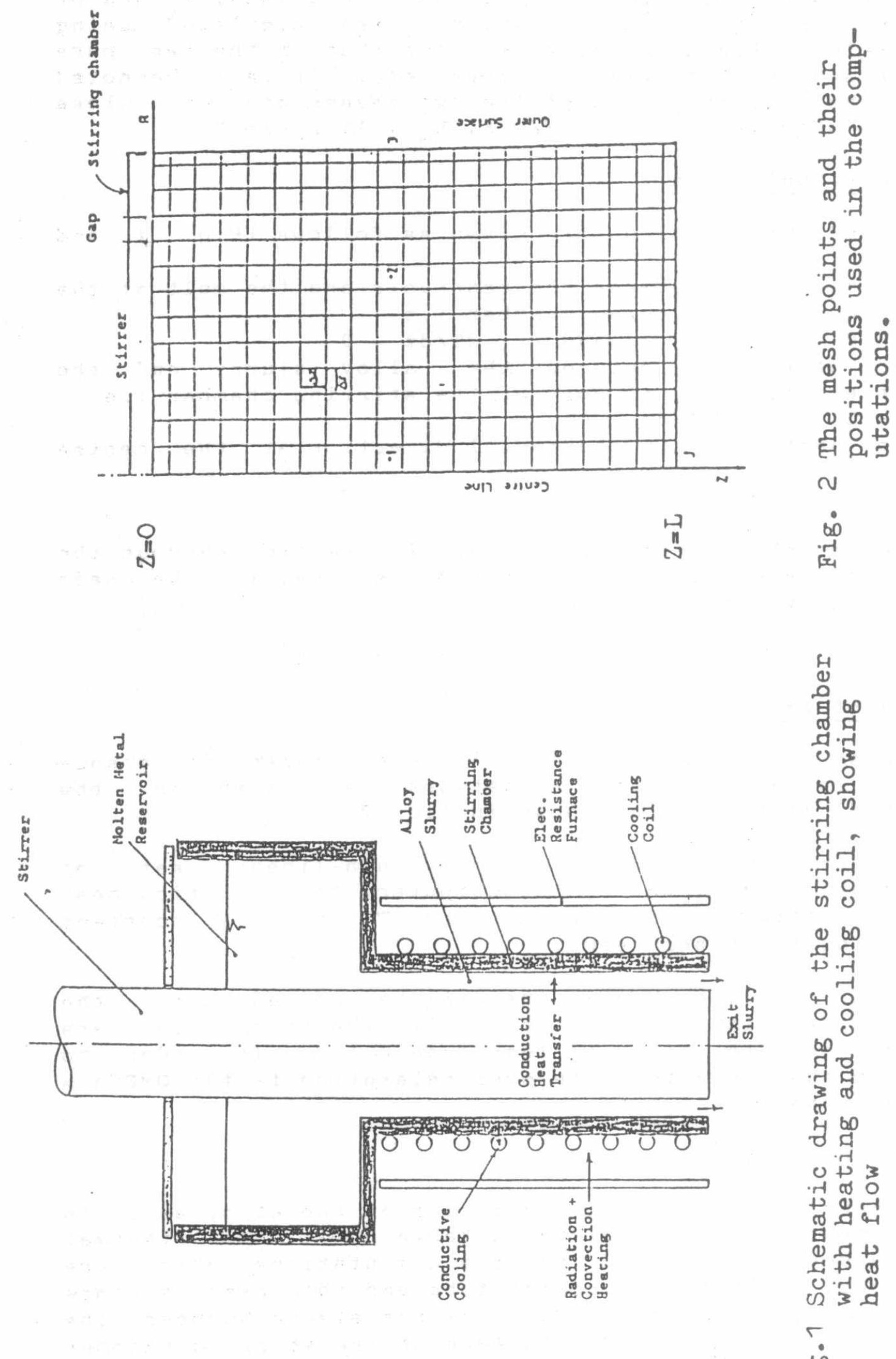
5. The thermal conductivity of the liquid metal k, and of the mixture of liquid plus solid k are calculated using the rule of linearity mixture using that of the two pure metals and the two phases respectively. It is to be noted that the conductivities of the two phases are very close to each other $\left(K_{1}=10.1 \mathrm{~W} / \mathrm{m} \mathrm{K}, \mathrm{K}_{\mathrm{m}}=10.2 \mathrm{~W} / \mathrm{m} \mathrm{K}\right)$.

Boundary Conditions: -

The boundary conditions are given as follows (Fig. 1 and 2) :

a) No heat flow between the reservoir and the melt at the entrance of the stirring chamber i.e.
at $\mathrm{Z}=0$
$\mathrm{T}=\mathrm{T}, \quad$ and
$\mathrm{d} \mathrm{T} / \mathrm{dz}=0$

b) No heat flow between the alloy slurry and the atmosphere at the exit port of the stirring chamber i.e.: at $z=L \quad d T / d z=0$

c) No heat flow in the radial direction at the centre line of the gtirrer i.e.:

at $r=0 \quad \mathrm{dT} / \mathrm{dr}=0$

d) The amount of heat flow in radial direction through the outer surface of stirring chamber is equal to the heat extracted by the cooling system i.e.:

at $r=R_{2}, \quad d T / d r=Q \quad$ and $d^{2} T / d r^{2}=0$

Method of soluti으므:

In order to solve equation (1), the finite difference method is applied and a network is placed on the longitudinal section as shown in fig. 2 .

In order to solve the highly non-linear set of différential equations by the computer, the radiation heat transfer term $T$ is replaced by $T$ times a constant containing the other terms.

The set of linear equations will be solved using the Gauss-Seidel iterative method ( 13 ). The interation were stoped when the error is less than $0.1 \mathrm{~K}$. In order to speed up the iteration, an over relaxation factor OMEGA = 1 . 1 was used.

\section{Thermal parameters:}

The thermal and physical properties of the alloy used in the computations are given in table (1). Some thermal resistances are needed for the computations which are resistance between the copper tube and the outer surface of the stirring chamber ETA, the resistance between the alloy slurry and the inner surface of the stirring chamber 


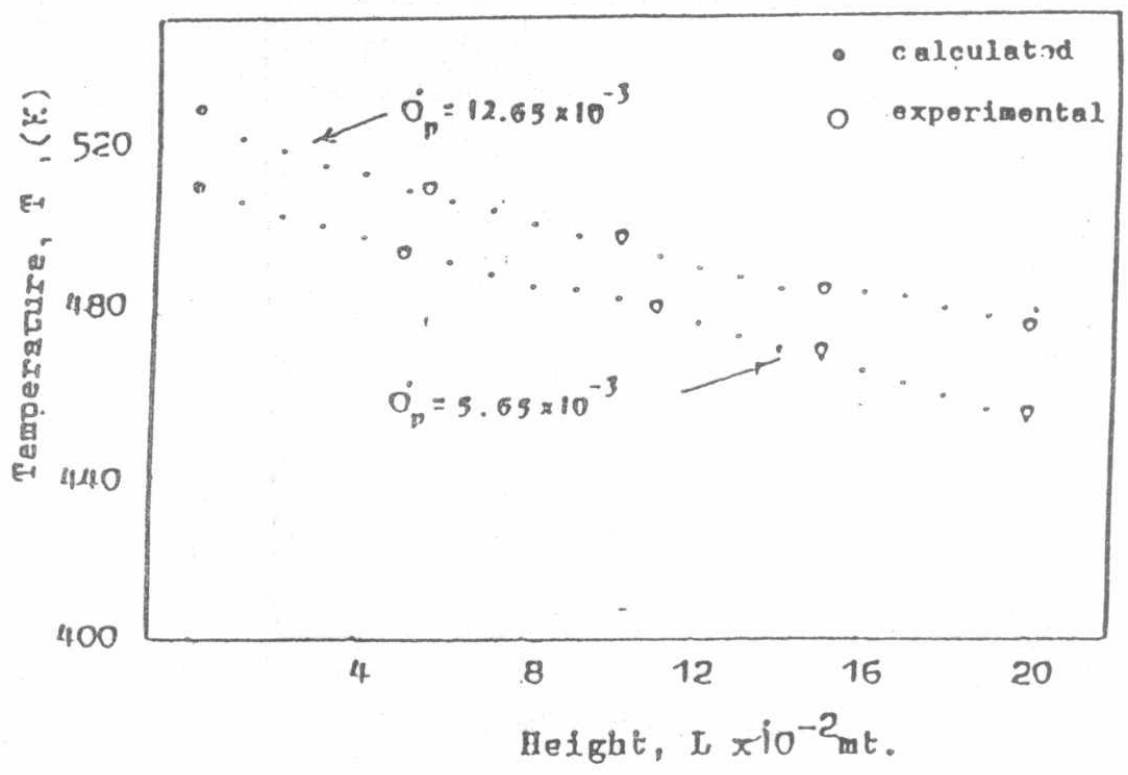

Fig. 3 Experfmental and.calculated temperature distrfbution of B1-17\%wt Su slurry along the helgbt of the otfrring chamber at two values of llow rate of $5.65 \times 10^{-5}$ and $12.65 \times 10^{-5} \mathrm{Kg} / \mathrm{s}$ and shear rate of $2701 / 8$.

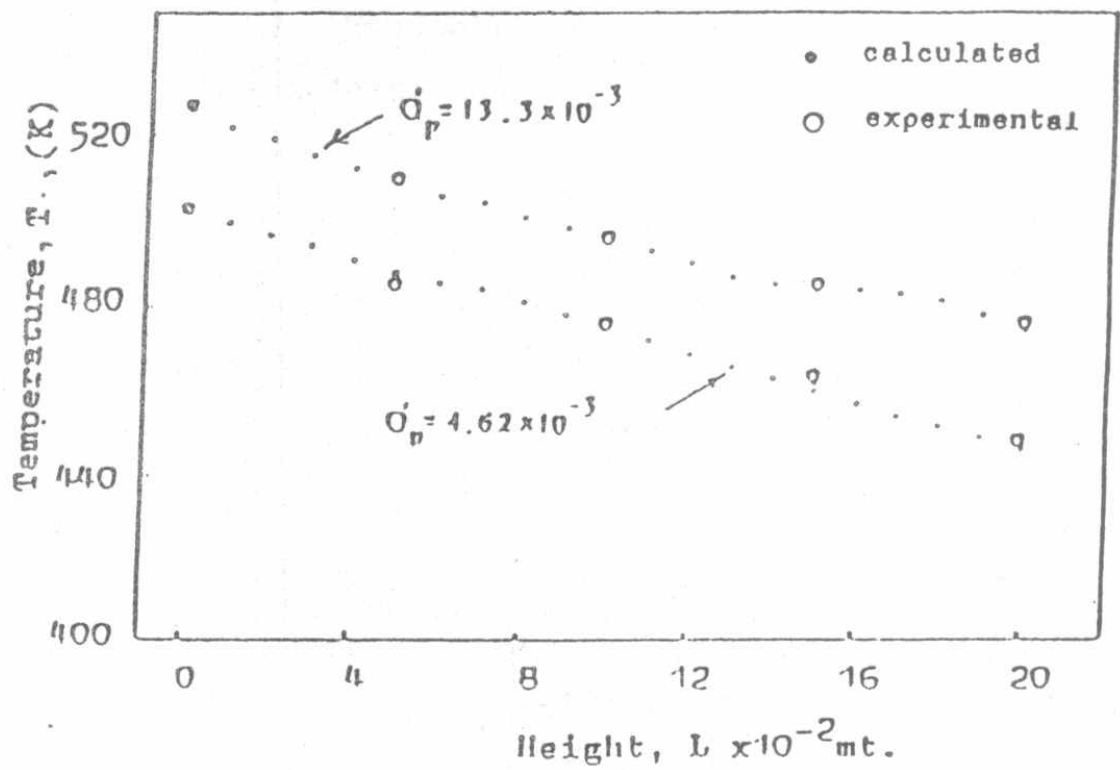

Flg. 4 Experfmental ond calculated temperature dfatribution of Bi-17\%wt. Un slurry nlong the betglit of the stirring chamber ot two valueg of rlow rate of $11.62 \times 10^{-3}$ and $13 \times 10^{-3} \mathrm{Kg} / \mathrm{s}$ and shonr rate of $450 \mathrm{1/8}$. 


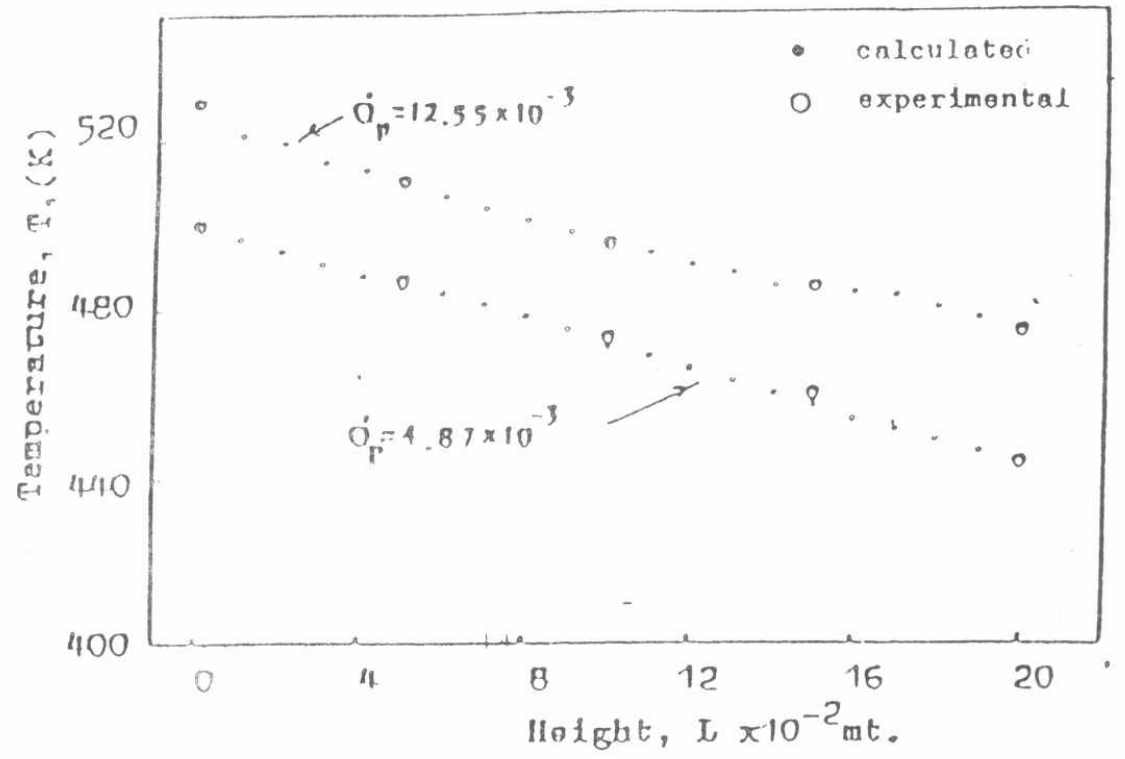

Flg.5 Experfmental and calculated temperature distribution of Bi-17\%wt Sn slurry elong the height of the stirring chamber at two volues of llow rate of $4.87 \times 10^{-3}$ and $12.55 \times 10^{-3} \mathrm{Kg} / \mathrm{s}$ and shear rate of $675 \mathrm{l} / \mathrm{s}$.

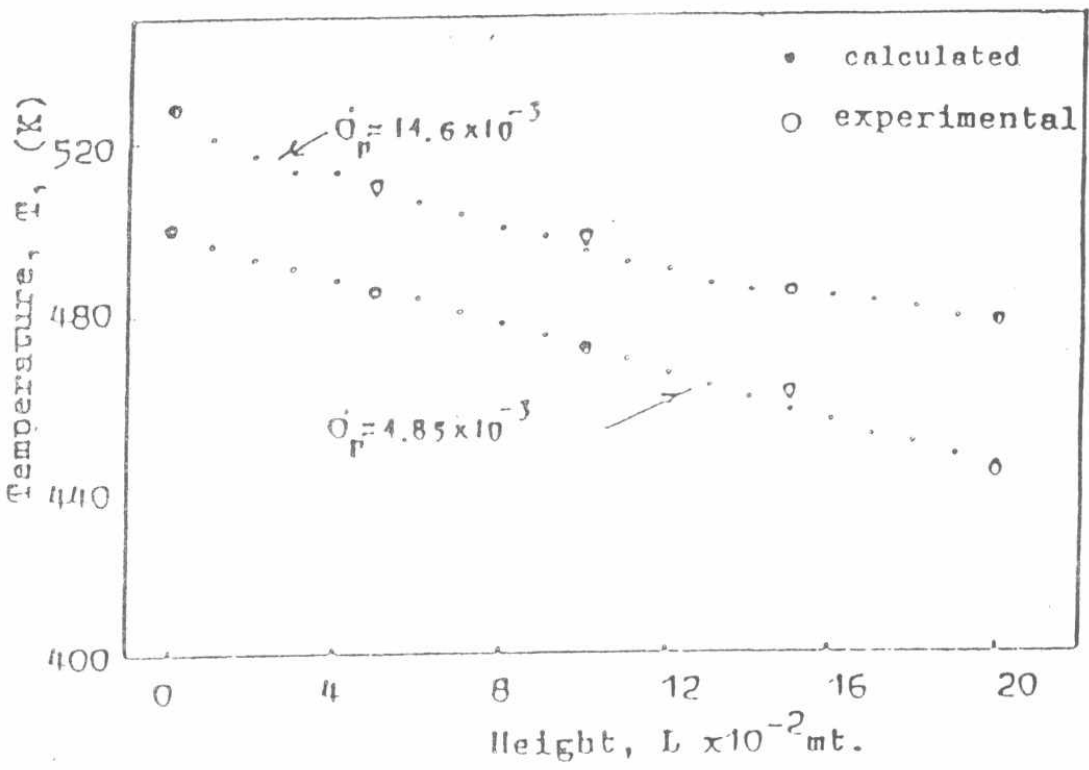

Fig. 6 Experimental and calculated lemperature diatributinn of Bi-17?

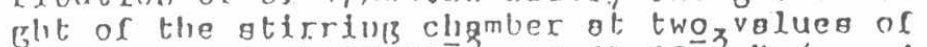
flow rate of $4.05 \times 10^{-3}$ and $11 \times 10^{-3} \mathrm{Kg} / \mathrm{g}$ and shear rate of $9001 / 8$. 
in terms of temperature distribution along the axis of the stirring chamber and the computed results for two different flow rates are presented in fig. 3 to 6 . The best fittig between the experimental and computed results gave the following values of heat resistances:-

ETA $=1 \times 10^{-3} \mathrm{~m}^{2} \mathrm{k} / \mathrm{W}$, GAMA $=$ PHI $=0 \mathrm{~m}^{2} \mathrm{~K} / \mathrm{W}$

Table (1): Physical properties of Bi-17/wt pet sn alloy[14]

Thermal conductivity of the liquid alloy

For $T$ in the range $486-573 \mathrm{~K}$

Thermal conductivity of the solid alloy

For $T$ in the range $486-433 \mathrm{~K}$

Density of the alloy

Latent heat of fusion

Melting point

Specific heat

$$
\begin{aligned}
& 10.1\left(\mathrm{w} \mathrm{m} \mathrm{m}^{-1} \mathrm{~K}^{-1}\right) \\
& 10.2\left(\mathrm{w} \mathrm{m}^{-1} \mathrm{~K}^{-1}\right) \\
& 9.3 \times 10^{3}\left(\mathrm{Kg}^{-1} \mathrm{~m}^{-3}\right) \\
& 39501(\mathrm{~J} \mathrm{Kg}) \\
& 486 . \mathrm{K}\left(\mathrm{J} \mathrm{Kg}^{-1} \mathrm{~K}^{-1}\right) \\
& 180.4\left(\mathrm{~s} \mathrm{~K}^{-1}\right.
\end{aligned}
$$

EFFECT OF STIRRING CHAMBER DIMENSIONS ON EXIT TEMPERATURE:

The dimensions of the stirring chamber which have the main effect on the exit temperature and the corresponding volume of solid fraction are the height of the stirring chamber and the number of cooling coils per unit height of the stirring chamber. As the cooling rate is slow in the atirring chamber the solidification of the alloy is considered under equilibrium condition, and the phase distribution in the mushy zone can be calculated using the lever rule. The relation between the temperature, $T$ and fraction solid, $G_{8}$ is given by:-

$$
G_{s}=1-48.5 /(261.5-T)
$$

The effect of the height of the stirring chamber, L, on the exit temperature, $T$ exit, and the corresponding volume fraction solid, $G$ is shown in fig. 7 . At the same number of cooling goils pe̊r unit height, $\mathrm{N}=50$, flow rate, $Q_{0}=$ $9 \times 10^{-3} \mathrm{Kg} / \mathrm{s}$ and at differgnt values of input temperatures, $T_{i}$, the exit temperature decreases with increasing the hểight, L. This result is reasonable since the amount of heat extracted from the outer surface of the stirring chamber increases with the height L. The effect of $L$ on $t$ exit is more pronounced at lower $T_{i}$ and at higher $\mathrm{L}$ values. For example at $\mathrm{T}$. $=500 \mathrm{~K}$ T ${ }^{i}$ decreases from 478 to $447{ }_{3} \mathrm{~K}$ with increasing the heightett from $8 x$ $10^{-3}$ to $20 \times 10^{-3} \mathrm{mt}$, and at $\mathrm{T}=5309 \mathrm{~K}$, T exjt-gुecreases from 482 to $472 \mathrm{~K}$ with increasing L from $8 \times \mathrm{e}^{x}+f^{-3}$ to $20 \mathrm{x}$ $10^{-3} \mathrm{mt}$. 


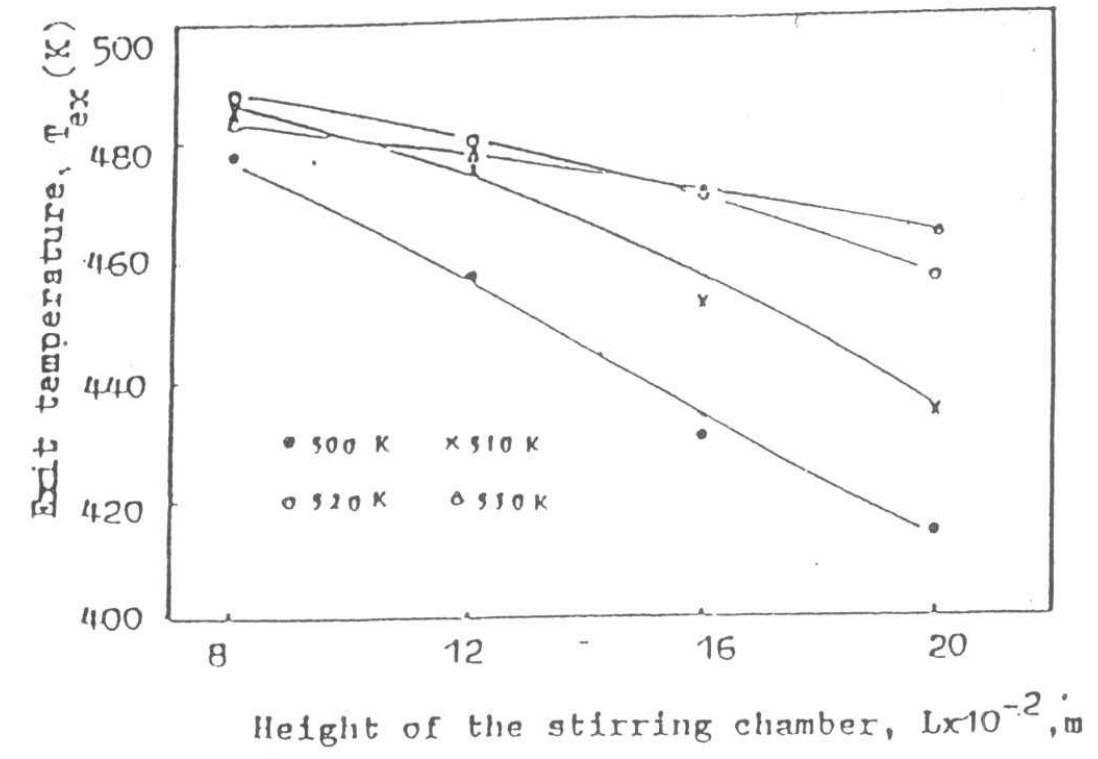

Fig.? Effect of height of the stirring chamber, $t$ on $T_{\text {exit }}$ t. $\mathrm{N}_{\mathrm{g}}-50 \mathrm{1} / \mathrm{m}$ and $\mathrm{Q}_{\mathrm{p}}=9 \times 10^{-3} \mathrm{Kg} / \mathrm{s}$ and different values of $\mathrm{T}_{1}$ of $500,510,520$ and $530 \mathrm{~K}$.

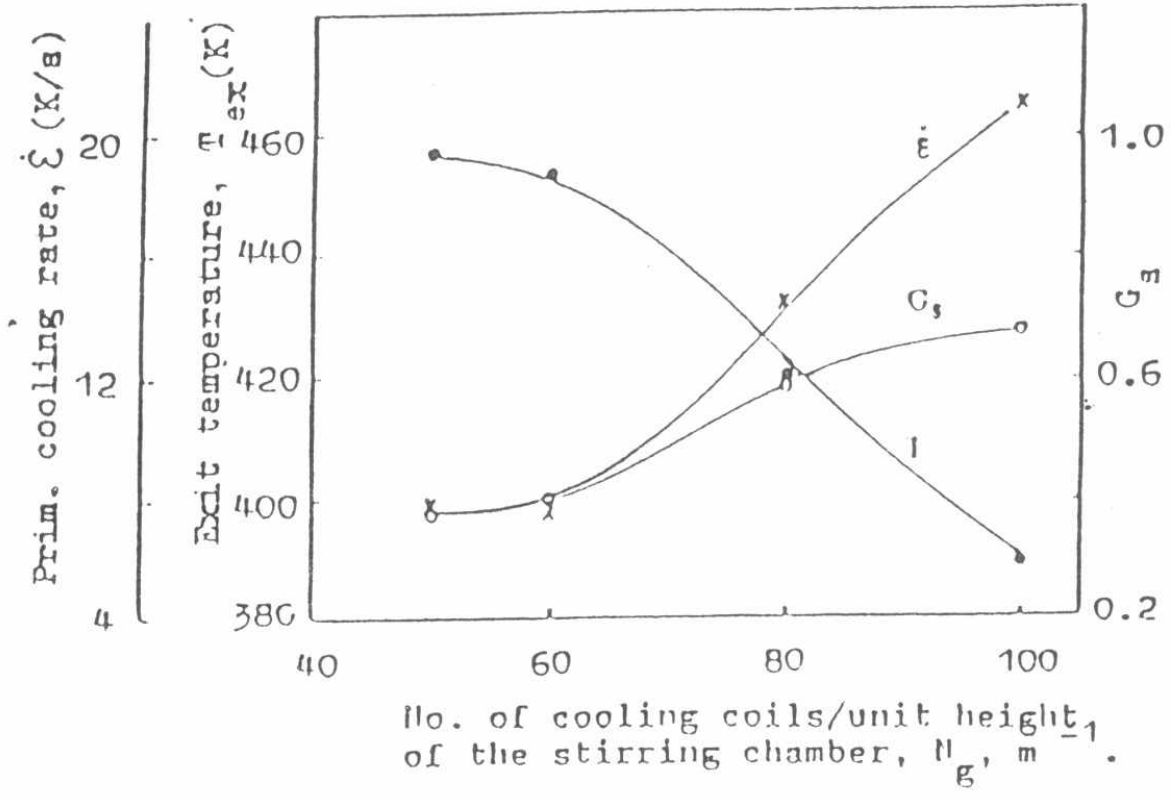

Fig. 8 Ecrect of no. of cooling coilsiunit height of the stirrine chanber "g on $E$, Texit and $\mathrm{G}_{s}$ at $\mathrm{L}=0.2 \pi, 0_{p}-0_{0}, \mathrm{C}^{-3} \mathrm{C}^{-3} \mathrm{i}_{\mathrm{E} / \mathrm{s}}$ and $T_{1}=5.10 \mathrm{k}$. 


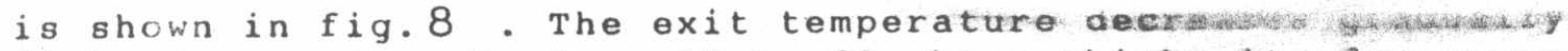
with ncreasing $N$ from 50 to 60 above which it decreases rapidl till $390{ }^{g_{K}}$ at $N=100$. The corresponding solid fracitc $G$ at the exit port increased from 0.39 to 0.65 by increas ag f from 50 to 100 . As the ptimary cooling rate has the major ef pect on the structure of the rheocast material it is found that $E$ increases from 8 to $21 \mathrm{~K} / \mathrm{s}$ as $N$ incrases from to 100 . These behaviour is reasonable since at high $T$ T is small and as the flow rate is kept constant, thexitesulting cooling rate $E$ will be lower. The values of $E$ are plotted for different $\mathrm{N}_{\mathrm{g}}$ in fig. 8 .

EFFECT OF INPUT TEMPERATURE AND METAL FLOW RATE ON THE EXXIT TEMPERATURE AND THE CORRESPONDING SOLID FRACTION*

Fig. 9 shows the effect of input temperature $T i$ on the exik temperature, volume fraction solid and the primary cooling rate. Increasing $T$ from 500 to $530 \mathrm{~K}$ leads to an almost similar of $T$ from 447 to $472 \mathrm{~K}$ therefore a corresponding decrease in Gif from 0.44 to 0.22 . Also, the cooling rate decreases from 9.1 to $3.55 \mathrm{~K} / \mathrm{s}$ shows the effect of the metal flow rate, $Q_{p}$ on 'Texit, $G_{g}$ and $E$.

Increasing of $Q$ leads to increasing both $T$ exit and $E$ and to decreasing $\mathrm{s}_{\mathrm{s}}$. From the figure it is observedithat increasing Q from $1 \times{ }^{8} 10^{-3}$ to $13 \times 10^{-3} \mathrm{Kg} / \mathrm{s}$ results in increasing of Texit at different ${ }^{N}$ values. It is clear that $Q_{p}$ has a pronounced effect on $\mathrm{T}$ exit at $\mathrm{N}_{\mathrm{g}}=80$.

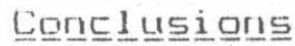

From. the above results and discusions the following conclusions can be drawn:

The slurry exit temperature and corresponding Gs, is inainly affected by the melt input temperature Ti, and the number of cooling coils per unit height of the stirring chamber Ng. It is also affected by the slurry flow rate $0 p$ and the height of the stirring chamber L. The exit temperature increases with increasing $\mathrm{Ti}$ and $\mathrm{Op}$, and decreasing $\mathrm{Ng}$ and $\mathrm{L}$. 


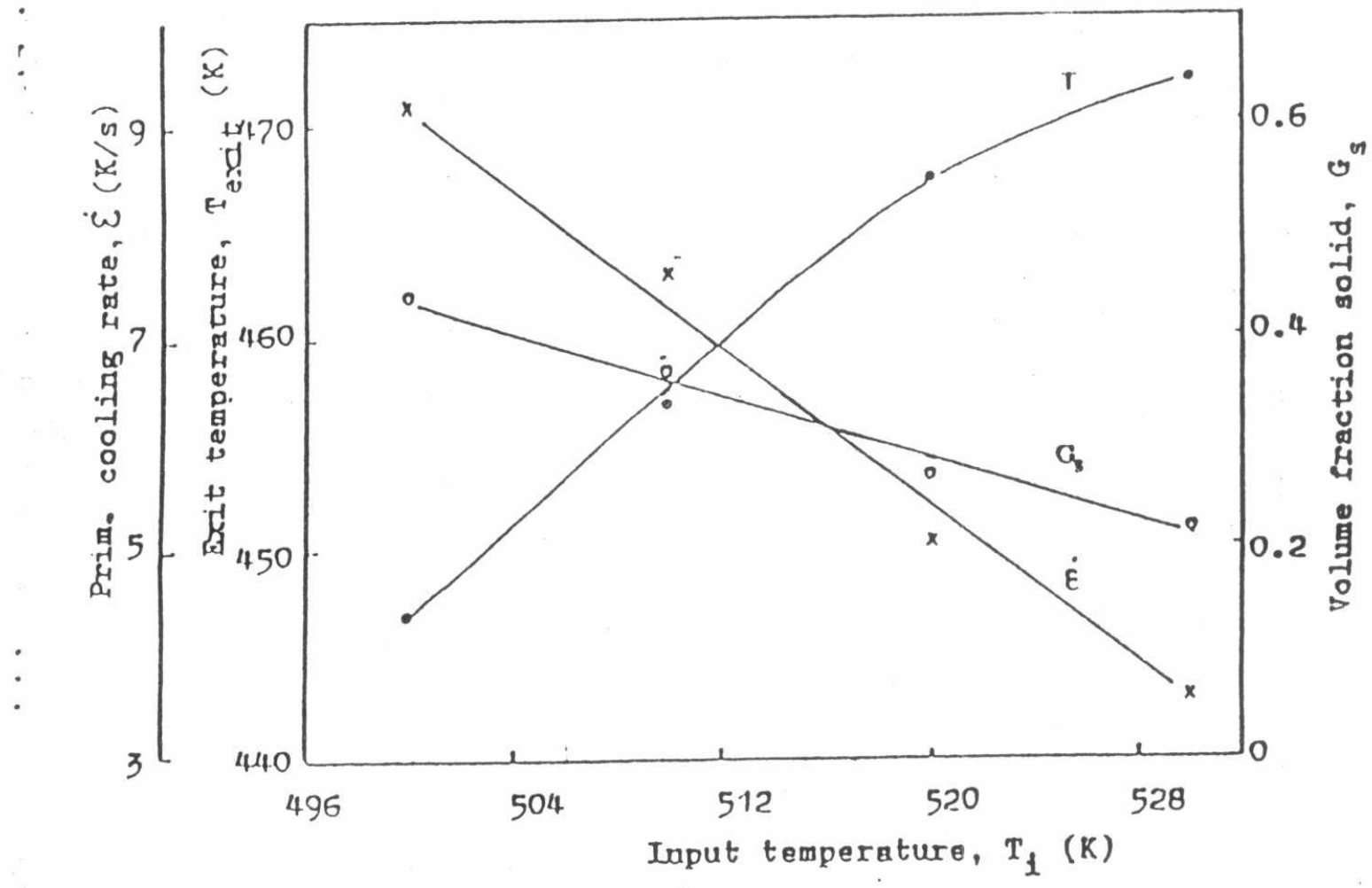

F15. 9 Erfect of input temperature $\mathrm{T}_{1}$ on $\dot{\varepsilon}$. T exit and $G_{s}$ at $L=0.2 \mathrm{~m}, Q_{p}=9 y^{-10^{-3}} \mathrm{Kg} / \mathrm{s}$ and "g" $501 / \mathrm{m}$. 


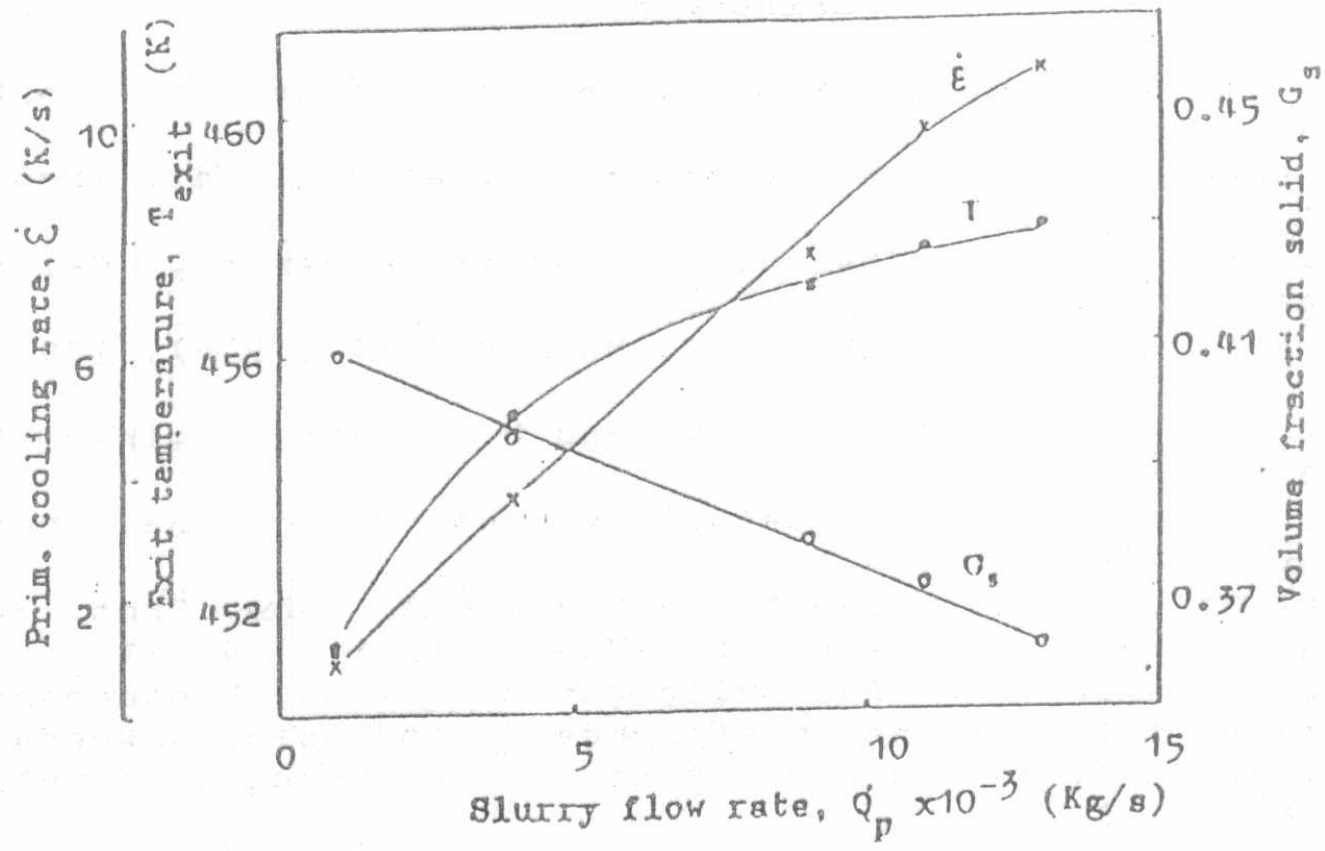

Fig. 10 Exfect of slurry flow rate $Q_{p}$ on $\mathcal{E}, T_{\text {exit }}$
and $G_{g}$ at $L=0.2 \mathrm{~m}, \mathrm{~T}_{1}=510 \mathrm{~K}$ and $\mathrm{N}_{\mathrm{B}}=501 / \mathrm{m}$

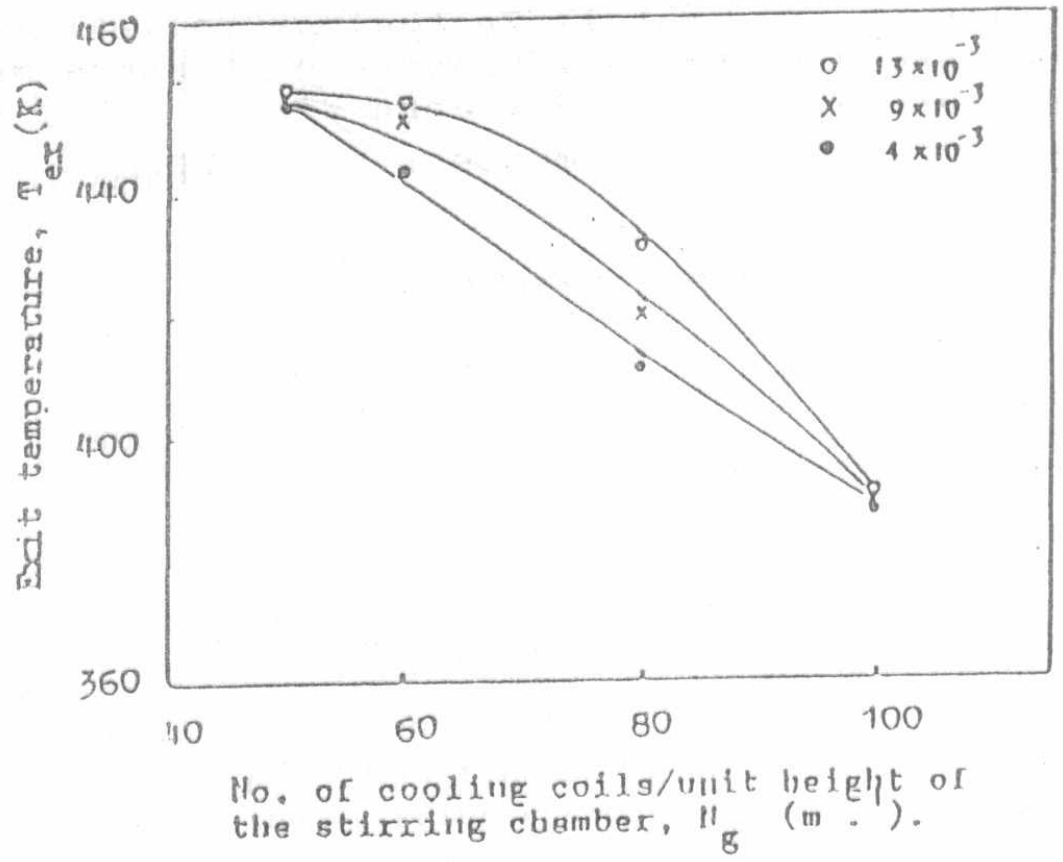

Fig. 11 Brfect of $\mathrm{N}_{\mathrm{g}}$ on $\mathrm{T}$ ext at $\mathrm{l}=0.2 \mathrm{~m}$ and different values of $Q_{p}$ of $13 \times 10^{-3}, 9 \times 10^{-3}$ and $11 \times 10^{-3} \mathrm{Ke} / \mathrm{s}$. 
1. N.A. El-Mahallawy and M.A. Taha, J. of Metals, Sept. $(1985), 42-46$.

2. D.B. Spencer, R. Mehrabian and M.C. Flemings. Met. Trans. $3,(1972), 1925-32$.

3. A.M.Assar, Ph.D., Thesis, Ain Shams University, Cairo, Egypt $(1985), 35-65$.

4. P.A. Joly and R. Mehrabian, J. Mat. Sc. $11(1976), 1393-$ 1418 .

5. A.M. Assar, N.A. El-Mahallawy and M.A. Taha, Aluminium 57 (1981) $807-810$.

6. A.M. Assar, N.A. El-Mahallawy and M.A. Taha, Met. Technology, $9(1982) 165-170$.

7. A. El-Sawy, N.A. El-Mahallawy and M.A. Taha, Proc. 7th Int., Light Metal Congress (Leoben-Wien) (1981) $114-115$.

8. N.A. El-Mahallawy, N. Fat-Halla and M.A. Taha, Proceedings of the fourth International Conference, stockhollm, Sweeden, edited by J. Carlson and N.G. Ohlson, 15 - 19 August (1983), Vol. 23, 695- 702 .

9. M.A. Taha and N.A. El-Mahallawy, Proc. $3^{\text {rd Int. Conf. on }}$ Mechanical behaviour of 'material, (ICM3), Cambridge, U.K. (1979) Vol. 2, 537 .

10. M.C. Flemings and R. Mehrabian, ASM, Metal Park, Ohio, (1976) P. 98. P. $203-213$.

11. M.A. Taha and N.A. El-Mahallawy, Advanced Technology of plasticity 1984 , Vol. 1 .

12. M.A. Taha and M. Suery, Metals Technology Vol. 11 (1984). 13. G.E. Forsythe and W.R. Warsow, "Finite difference methods for partial differential equations", John Wiley, N.Y., 1959. 14. Thermophysical properties of matter, Vol.4 pp.22, Vol.1 pp. 511. 